\title{
The Degree to Which Science Teachers in the Upper Basic Stage Practice the Required Roles in Light of the Digital Age Demands amidst COVID-19
}

\author{
Fawaz H. Shhadeh ${ }^{{ }^{*}}$, Tasneem Alhalalmeh ${ }^{2}$ \\ ${ }^{1}$ Amman Arab University, Jordan- Amman \\ ${ }^{2}$ University of Jordan, Jordan- Amman
}

\begin{abstract}
The present study aimed to investigate the degree to which science teachers in the upper basic stage practice the required roles in light of the digital age demands amidst COVID-19. To that aim, the descriptive survey approach was used in addition to a questionnaire of 30 items spread over 3 domains: technological, social and research, in a form of scale developed distinctly for gathering data. Reliability and validity of these items were verified. The sample of the study consisted of (143) male and female science teachers. The statistical treatment of data involved using the means, standard deviations, and three-way MANOVA. The results of the study showed that the degree to which science teachers in the upper basic stage practice the required roles in light of the digital age demandsamidstCOVID-19pandemic was moderate. Technological domain ranked first with a mean of (3.90) and got a high degree. Social domain ranked second with a mean of (3.31) while Research domain ranked last with a mean of (2.54) and both got a moderate degree. The findings also indicated that there were no statistically significant differences in the science teachers 'practice attributed to the variables of gender, experience and education sector. The study reached several recommendations, the most important of which is educating teachers about the importance of practicing the required roles in light of the digital age demands amidst COVID-19 pandemic.
\end{abstract}

Keywords: COVID-19, Digital age demands, Required roles, Science teachers.

\section{INTRODUCTION}

Recently the world has seen a dramatically accelerating pace in the development and adoption of new technologies, big data analytics, cloud computing, Internet of things, robotics and digital transformation which have raised expectations on how these new technologies will change the future of work and life in the digital economy. Each period of development brings with it new challenges for producing significant change; and educationally, contemporary societies need to create a new type of education to grasp the information and communication technology, provides learners with a critical and conscious mind, goes beyond the limits of time and place and doesn't require the presence of the teacher and learners in the same place.

In light of the digital revolution that swept the entire world, digital media cannot be avoided because they have become essential for survival. Every corner of the world has been reached by this system, digital life has encircled all aspects of life, and the details of daily life have been transformed into digital practices. Consequently, and due to the massive technical revolution and the successive demands of education in the digital era, consensus has grown about the kinds of changes needed to enhance high-quality teachers to make education more effective and coexist with all global changes, to simulate tangible reality and promote creativity and innovation. It has become imperative to work on providing the teacher as an agent of change with new skills to adapt his practices to better integrate technology into the classroom, especially after the overwhelming consequences of COVID-19 pandemic, which has sent shockwaves across various sectors one of which is education (Al-Ghamdi and Ruwaili, 2020; Yildırım and Mirici).

Many educational systems in various countries have been negatively affected by the current global crisis, and the need has become urgent to rely on innovative digital strategies and effective teaching and learning methods, in addition to enhancing the skills of the academic staff and supporting their shifting to digital education(Atteberry\&McEachin, 2020).

Given that digital variables have played a vital role in this new era of innovation, the changes are profoundly exciting and there is an urgent need to develop educational

Corresponding Author e-mail: fwaz1975@yahoo.com https://orcid.org/0000-0001-5119-1095

How to cite this article: Shhadeh FH, Alhalalmeh T (2022). The Degree to Which Science Teachers in the Upper Basic Stage Practice the Required Roles in Light of the Digital Age Demands amidst COVID-19. Pegem Journal of Education and Instruction, Vol. 12, No. 1, 2022, 149-158

\section{Source of support: Nil}

Conflict of interest: None.

DOI: $10.47750 /$ pegegog.12.01.14

Received: 29.08.2021

Accepted: 02.11.2021 Publication: 01.01.2022 
institutions to keep pace with those changes. This has resulted in the emergence of modern skills, roles and patterns of competencies that aim to increase the quality of educational output, represented in the effective use of innovations in the educational process(Balawi, 2019).

In order to keep pace with these developments and challenges, science teachers in the current century must practice new roles and possess a set of competencies, foremost of which are digital competencies, so that they can play effective roles in preparing to coexist with the new challenges and technologies. Since the most important factor in the equation is unequivocally the student! This requires reconsidering both the nature of today's student and future, in addition to reconsidering the teacher's roles to face their new assignments and keep pushing the student onward as well as upward (Anil, 2019).

The digital age is the era people live in today. It is all advanced devices and digital products that use computers and other technology devices as medium of communication which clearly indicates the control of digital means in the field of communication, processing and exchanging information. The digital era is characterized by technology that increases the speed and breadth of knowledge turnover within societies and will increase as technological functionality becomes more knowledge-based. It also is characterized by accuracy and killing of distances and borders, and will ensure building sustainable relationships with both technology and the advanced knowledge that technology helps to create.

Based on the foregoing, the researchers conclude that the teachers' roles in light of the digital age requirements amidst (COVID-19) are changing, and so are expectations about them, they are closely related to the sweeping technological change which calls on experts to maintain teacher quality and educational effectiveness.

The pandemic has demonstrated that having an education and training system which is fit for the digital age is essential. Accordingly, it is very important to provide science teachers with training and overall levels of digital skills and competences to meet the requirements of the digital age and to interact positively with the quality of new education.

A plethora of research has been conducted to investigate teachers' roles in the digital age. Al-Olaymat (2020) carried out a study to know the degree to which science teachers practice the education technology competencies. The descriptive approach was used, in addition to a 31-competency questionnaire. The study sample consisted of (150) male and female teachers in Al-Balqa Governorate. Statistically, means, standard deviations, and t-test were used. The results indicated that the degree to which science teachers practice the education technology competencies is moderate, the results also showed that there were no statistically significant differences in the degree to which they practice the education technology competencies attributed to gender and experience.
Al-Yami(2020) conducted a study aimed at identifying the reality of female teachers' possession of digital teaching skills in the twenty-first century. It also sought to determine the degree of their training needs from their point of view in public education institutions. The study used the descriptive approach, and a 64-items questionnaire developed and applied to a random sample of (174) principals and (981) female teachers. The results concluded that the female teachers' possession of digital teaching skills was moderate, and that the training needs were very large.

Al-Rasa'I (2017) investigated the competencies of science teachers in the field of information and communication technology. The analytical descriptive approach was used in addition to a scale built to measure the concerned competencies. The study sample consisted of (163) graduated students from science faculty at Al Hussein Bin Talal University in Jordan. The results revealed that the degree of teachers' possession of ICT competencies was low on the instrument as a whole. More specifically, the degree was moderate in the domains of ICT skills and ICT ethics, while it was low in the domain of ICT culture and its employment in teaching.

Al-Hayiki (2017) conducted a study aimed at identifying the level of digital empowerment in education among middle school teachers in the Kingdom of Bahrain. The study used the descriptive approach and a sample of (35) teachers distributed over five middle schools. The results indicated that the level of digital empowerment for middle school teachers was high.

Zaragoza, at el., (2019) examined the reality of competencies that teachers need in the digital age and whether they possess them or not. The study used quantitative and qualitative methods. (281) school principals responded to a questionnaire and (29) of them were interviewed. The results of the study revealed the critical need of today's teachers for a mix of competencies that have always been the mark of a good teacher, especially in the field of personal competencies and relationships. Moreover, the professional development of the teacher will reflect positively on both his social and emotional competencies and the proper management of the classroom.

Stols et al., (2015)explored the perceptions of mathematics teachers' need for training to use technology in classrooms in South African. The sample consisted of (22) teachers. Both quantitative and qualitative approaches were used, in addition to a questionnaire to measure the degree of their need. The results showed that there is a crucial need for training on how to use technology in education to expand teachers' mathematical knowledge and develop their teaching strategies, since they lack the necessary skills to employ technology in teaching-learning process.

A good body of research, which varied in scope and objectives, was reviewed for the purpose of the study. Some investigated the degree of availability of ICT competencies among science teachers, such as Al-Rasa'i (2017). The present 
study aimed to explore the degree to which science teachers in theupper basic stage practice the required roles in light of the digital age demands amidst COVID-19. All previous researches were similar in terms of using the questionnaire as the instrument of the study.

The current study benefited from previous studies in presenting and enriching the theoretical literature, developing the study instrument, determining the methodology used and discussing the results. To the best of the researcher's knowledge, this study is the first of its kind to examine the degree to which science teachers at the upper basic stage practice the required roles in light of the digital age demands amidst (COVID-19) pandemic.

\section{Problem of the Study}

Due to corona pandemic, the total closure of schools in some countries is impacting over $60 \%$ of the student population. In order to contain the contagion, many countries have implemented restrictive measures to reduce gathering and formations of crowds. Schools are also affected and had to reduce their classes or close entirely. Luckily, education did not grind to a halt, but it transformed and moved online. The world have moved towards digital learning, and made distance education a basic alternative to the face to face education.

Educational systems in various countries of the world need to think outside the box. To appropriately switch to online learning, three requirements need to be fulfilled: access to the internet, the right technology, and the skills and competencies to use the technology.

The studies of yue (2019) and Al-Rasa'i (2017) recommended that pre and in-service teachers need to possess a high level of adequate digital competencies, and to be trained on practical applications and produce educational materials in various disciplines.

Under the climate with changing learning modes in science which has become a common trend globally; it is inevitable for science teachers integrating information technology into subjects to assist in students' learning with teaching materials, teaching methods, and diversified teaching media. Therefore, attention should be paid to developing the digital competencies of science teachers; to be able to employ technological applications and digital learning resources in teaching; which contribute significantly in meeting a wide range of goals and improving the quality of the educational process. Furthermore, it is necessary for every science teacher who wants to enter the world of education in the digital age to be aware of the basic requirements, facts and challenges that underpin this modern type of education, in order to be able to actually engage, integrate and create.

Digital competences are one of the ways to improve teachers' performance, since they affect their behavior, improve their performance and help to create harmonious work relationships.
Accordingly, the study aims to recognize the most important roles that science teachers need in light of the digital age requirements amidst Corona pandemic through answering the following questions:

- To what degree do science teachers in the upper basic stage practice the required roles in light of the digital age demands amidst COVID-19?

- Are there any statistically significant differences $(\alpha=$ $0.05)$ in the degree of science teachers' practice from their perspectives due to (gender, years of experience and education sector) variables?

\section{Significance of the Study}

The findings are expected to provide potentially significant information on the importance of the digital competencies that teachers preparation programs need, and the role of these competencies in keeping pace with developments, improving school performance, supporting teaching practice and providing effective strategies and techniques during teaching and learning process.

It may also contribute to the development of workers' capabilities and their possession of technological competencies, especially science school teachers. The study is hoped to assist decision-makers in the educational field to include these skills in the field training of universities.

The study may also benefit science teachers in developing their teaching strategies, directing their attention to the importance of integrating modern and effective strategies in the classroom. Moreover, it may also represent a response to the changes and developments of the twenty-first century that impose renewal in the skills, abilities and competencies of science teachers.

\section{Limitations}

The study was limited to a sample of science teachers in Amman governorate, the first semester of the academic year 2020/2021 and the degree to which the sample represents the population. It is also limited to a group of roles required in light of the digital age demands amidst COVID-19. . Therefore, these two limitations lead well to future researches.

\section{Method}

The current study used the descriptive survey approach, whereby the degree to which science teachers practice the required roles in light of the digital age demands amidst COVID- 19 was measured through an instrument prepared by the researchers after extracting its psychometric properties.

\subsection{Participants}

The study population consisted of all science teachers in WadiAseer district in the academic year 2020-2021 $(\mathrm{N}=313)$. 
The study sample consisted of male and female teachers who were drawn from the study population by the simple random method $(n=143)$ and formed $(45 \%)$ of the study population. Table (1) shows the distribution of the study sample according to its variables.

\section{Study Instrument}

Based on an extensive review of the literature and to achieve the objectives of the study, a questionnaire was developed to measure the degree of science teachers' practice. It consisted of thirty paragraphs and three domains: technological, social and research domain. 5-point likert scale was used which responders specify their level of agreement to a statement typically in five points: (1) Strongly disagree; (2) Disagree; (3) Neutral; (4) Agree; (5) Strongly agree.

\section{Validity and Reliability of the Instrument}

In order to examine the validity of the instruments, a panel of educational experts reviewed the instruments. The team was asked to validate the content of the instruments concerning its items, appropriateness to the purposes of the current study, the language clarity, and how well they represent the degree

Table 1: the distribution of the study sample according to its variables:

\begin{tabular}{lllll}
\hline$\#$ & Variable & & $N$ & $\%$ \\
\hline 1 & Gender & Male & 78 & 54.5 \\
& & Female & 65 & 45.5 \\
& & Total & 143 & 100.0 \\
2 & \multirow{3}{*}{ Years of experience } & Less than 5 & 57 & 39.9 \\
& & $5-10$ & 39 & 27.3 \\
& & More than 10 & 47 & 32.9 \\
& & Total & 143 & 100.0 \\
& \multirow{3}{*}{ Education sector } & Private & 65 & 45.5 \\
& & Public & 78 & 54.5 \\
& & Total & 143 & 100.0 \\
\hline
\end{tabular}

to which science teachers in the upper basic stage practice the required roles in the digital age. The teams' comments and recommendations were studied carefully and taken into account in amending the final version of the instrument. The correlation coefficients $\left(\mathrm{r}^{\dagger}\right)$ for the instrument items were also calculated as shown in Table 2:

Table 2 shows that the correlation coefficient of the items ranged between $(0.39-0.89)$. While the correlation coefficient on the total degree ranged between $(0.32-0.79)$ that was considered suitable to conduct the study.

The internal consistency of the instrument domains was also calculated as shown in Table 3.

Table 3 shows that correlation coefficient of the degree to which science teachers practice the required roles in light of the digital age demands ranged between $(0.73-0.87)$, and Cronbach alpha reached 0.89 that was considered relevant to conduct the study.

The science teachers' responses were analyzed in terms of the five-point Likert scale; (strongly agree, agree, undecided, disagree, strongly disagree with the numerical values of five, four, three, two and one respectively) which was further categorized into three levels: high, intermediate, and Low degrees. Mean scores were valued against the following criteria: (1.00 - 2.33 as Weak; 2.34 - 3.67 as intermediate; 3.68 - 5.00 as Strong). The percentage was calculated according to the following equation: The highest value - The lowest value/ category number. In the present research, the highest value was 5 ; the lowest value was 1 ; and the category numbers were 3 . Thus, the appropriate class intervals were calculated as follows: $5-1 / 3=1.33$

\begin{tabular}{ll}
\hline Class intervals & Class \\
\hline $1-2,33$ & low \\
$2.34-3.67$ & medium \\
$3.68-5.00$ & high \\
\hline
\end{tabular}

Table 2: The correlation coefficients $(\mathrm{r} \dagger)$ for the instrument items

\begin{tabular}{|c|c|c|c|c|c|c|c|c|}
\hline Item no & $\begin{array}{l}\left(r^{\dagger}\right) \\
\text { in domain }\end{array}$ & $\begin{array}{l}\left(r^{\dagger}\right) \\
\text { in total degree }\end{array}$ & Item no & $\begin{array}{l}\left(r^{\dagger}\right) \\
\text { in domain }\end{array}$ & $\begin{array}{l}\left(r^{\dagger}\right) \\
\text { in total degree }\end{array}$ & Item no & $\begin{array}{l}\left(r^{\dagger}\right) \\
\text { in domain }\end{array}$ & $\begin{array}{l}\left(r^{\dagger}\right) \\
\text { in total degree }\end{array}$ \\
\hline 1 & 0.39 & 0.33 & 11 & 0.58 & 0.56 & 21 & 0.64 & 0.44 \\
\hline 2 & 0.41 & 0.32 & 12 & 0.81 & 0.79 & 22 & 0.77 & 0.61 \\
\hline 3 & 0.52 & 0.55 & 13 & 0.64 & 0.63 & 23 & 0.76 & 0.72 \\
\hline 4 & 0.72 & 0.67 & 14 & 0.74 & 0.72 & 24 & 0.71 & 0.50 \\
\hline 5 & 0.70 & 0.57 & 15 & 0.75 & 0.68 & 25 & 0.82 & 0.75 \\
\hline 6 & 0.64 & 0.54 & 16 & 0.81 & 0.68 & 26 & 0.63 & 0.66 \\
\hline 7 & 0.76 & 0.60 & 17 & 0.71 & 0.67 & 27 & 0.64 & 0.44 \\
\hline 8 & 0.89 & 0.72 & 18 & 0.71 & 0.60 & 28 & 0.71 & 0.67 \\
\hline 9 & 0.68 & 0.61 & 19 & 0.52 & 0.58 & 29 & 0.52 & 0.55 \\
\hline 10 & 0.71 & 0.66 & 20 & 0.64 & 0.44 & 30 & 0.72 & 0.67 \\
\hline
\end{tabular}




\section{Data Collection and Analysis}

In order to find out the degree to which science teachers in the upper basic stage practice the required roles in light of the digital age demands amidst COVID- 19, means and standard deviations of the study sample scores were calculated using SPSS statistics. To examine if there are any statistically significance differences attributed to gender (male, female) experience (less than 5 years, 5-10 years, more than 10) and education sector (private, public) three-way analysis of variance and multi analysis of variance were used.

\section{Study Procedures}

The following procedures were carried out in the course of the study:

- The researchers reviewed the related literature to narrow the topic and aggregate the theoretical and empirical research related to the topic.

- Using official correspondence form to facilitate implementing the study.

- The population and sample of the study were identified.

- The instrument of the study was designed.

- The validity of the instruments was established by a jury of experts.

- The reliability was verified by applying it to a pilot group of (30) science teachers.

- Distributing the study instrument on the study sample, which consisted of (143) male and female science teachers in Wadi Al-Seer District.

- The results of the study were obtained through appropriate statistical analyses.

- The findings of the study were analyzed and discussed according to the questions of the study.

- The recommendations were set based of the results of the study.

\section{Findings / RESULTS}

\section{Results of the first research question}

The first research question sought the degree to which science teachers in the upper basic stage practice the required roles in light of the digital age demands amidst COVID-19from their perspectives. In order to answer this question a quantitative analysis was conducted to interpret the results obtained through the questionnaire, as shown in Table 4.

Table 3: Internal consistency to the instrument domains

\begin{tabular}{lll}
\hline No & Domain & Internal consistency \\
\hline 1 & Technological & 0.87 \\
2 & Social & 0.78 \\
3 & Research & 0.73 \\
\hline Total degree of the instrument & 0.89 \\
\hline
\end{tabular}

Table 4 shows that Technological domain ranked first with a mean of (3.90) a standard deviation of (.598), and a high degree of practice. Social domain ranked second with a mean of (3.31) a standard deviation of (.671) and a medium degree of practice. On the other hand, Research domain received the lowest score and ranked last with a mean score of (2.54), a standard deviation (.857) and a medium degree of practice. The degree to which science teachers in the upper basic stage practice the required roles was medium. The average response on the scale as a whole got a mean score of (3.24) and a standard deviation of (0.528) which indicates a medium degree of practice.

Furthermore, means and standard deviations of the responses on the items of each domain were calculated as follows:

- Technological domain : The means and standard deviations scores for the responses on the items of technological domain were calculated as shown in Table (5):

Table 5 depicts that the average means related to the technological domain ranged between (3.37 - 4.21),from medium to high degrees. The score of the domain as a whole obtained a mean of (3.90) and a standard deviation of (0.598) which indicates a high degree of teachers' practice.

The first item in the Table "I use technology in teaching "ranked first with a mean of (4.21) and a standard deviation of (0.85), while item 7 "I produce videos to help students visualize science concepts." received the lowest score and ranked last with a mean score of (3.37), and a standard deviation of (1.05).

This result could be attributed to the fact that very significant changes are taking place in the teaching and learning processes because of the new relationship between science and technology that is going to be critical during the COVID-19 crisis. Technology has doubtlessly contributed to provide teachers with a huge variety of scientific resources, whether at home or school, in addition to designing lessons, homework, assignments, assessments and completing group projects among students via internet to suit the online learning. Also, technology has helped teachers to explore universal design for learning that uses digital material where possible and provides more flexibility and fewer barriers to learning. It has also accelerated the rate of teachers' engagement with technology who have gained skill sets useful for their teaching

Table 4: Means and standard deviations of the study instrument domains and the overall score of the scale

\begin{tabular}{|c|c|c|c|c|c|}
\hline$\#$ & Domain & Mean & $\begin{array}{l}\text { Standard } \\
\text { deviation }\end{array}$ & Rank & Degree \\
\hline 1 & Technological & 3.90 & .598 & 1 & High \\
\hline 2 & Social & 3.31 & .671 & 2 & Medium \\
\hline \multirow[t]{2}{*}{3} & Research & 2.54 & .857 & 3 & Medium \\
\hline & Instrument as a whole & 3.24 & .528 & & Medium \\
\hline
\end{tabular}


competencies. In short, Technology has become an important instrument for teachers and holds great promise for promoting learning and explaining the scientific material easily and conveniently.

- Social domain: The means and standard deviations scores for the responses on the items of social domain were calculated as shown in Table (6):

Table 6 shows that the average means related to the social domain ranged between (2.95-3.50) and a medium degree for all items. The score of the domain as a whole obtained a mean of (3.31) and a standard deviation of (0.671) which indicates a medium degree of teachers' practice.

Item 20 in the Table "I am convinced that employing information technology and the Internet in education is one of the most important indicators of transforming into an information society, which contributes to increasing the efficiency and effectiveness of education systems "ranked first with a mean of (3.50) and a standard deviation of (0.85), whileitem12" I see myself as a social leader in my words and actions" received the lowest score and ranked

Table 5: means and standard deviations scores for the responses on the items of the technological domain:

\begin{tabular}{|c|c|c|c|c|c|}
\hline \# & Items & Mean & Standard deviation & Rank & Degree \\
\hline 1 & I use technology in teaching & 4.21 & 0.85 & 1 & High \\
\hline 2 & $\begin{array}{l}\text { I employ technology in designing science lessons to overcome the } \\
\text { problem of static content and present it more effectively. }\end{array}$ & 4.09 & 0.94 & 3 & High \\
\hline 3 & $\begin{array}{l}\text { Periodic transformation from a transmitter of knowledge to a user of } \\
\text { technology, researcher and producer of knowledge. }\end{array}$ & 3.80 & 0.94 & 8 & High \\
\hline 4 & $\begin{array}{l}\text { I have a website on the Internet to communicate with my students } \\
\text { through which I put everything related to science. }\end{array}$ & 3.92 & 0.85 & 5 & High \\
\hline 5 & I use the virtual laboratory to prepare scientific experiments & 3.85 & 0.94 & 7 & High \\
\hline 6 & $\begin{array}{l}\text { I work on developing the mental skills of my students, urging them to } \\
\text { think scientifically }\end{array}$ & 3.90 & 0.91 & 6 & High \\
\hline 7 & I produce videos to help students visualize science concepts. & 3.37 & 1.05 & 10 & Medium \\
\hline 8 & $\begin{array}{l}\text { I expand the methods of technical presentation to cater for students } \\
\text { differences }\end{array}$ & 4.14 & 0.85 & 2 & High \\
\hline 9 & I help students access websites as references for science subjects & 3.72 & 0.95 & 9 & High \\
\hline \multirow[t]{2}{*}{10} & I use interactive electronic tests to evaluate my students & 4.00 & 0.82 & 4 & High \\
\hline & The total score of the domain & 3.90 & 0.598 & & High \\
\hline
\end{tabular}

Table 6: Means and standard deviations scores for the responses on the items of the social domain:

\begin{tabular}{|c|c|c|c|c|c|}
\hline \# & Items & Mean & Standard deviation & rank & Degree \\
\hline 11 & $\begin{array}{l}\text { The use of distance learning technologies will enable students to learn } \\
\text { and collaborate with teachers and students in other locations. }\end{array}$ & 3.42 & 1.01 & 4 & Medium \\
\hline 12 & I see myself as a social leader in my words and actions & 2.95 & 1.05 & 10 & Medium \\
\hline 13 & $\begin{array}{l}\text { I act as an academic advisor individually or in small groups to monitor } \\
\text { the progress of my students in their personal learning programs }\end{array}$ & 3.12 & 0.94 & 9 & Medium \\
\hline 14 & I deal positively with parents & 3.32 & 1.09 & 7 & Medium \\
\hline 15 & I preserve the student's national and cultural identity & 3.16 & 0.94 & 8 & Medium \\
\hline 16 & I work on providing my students with life skills & 3.49 & 0.91 & 2 & Medium \\
\hline 17 & $\begin{array}{l}\text { I disseminate the concepts of culture and dialogue management } \\
\text { among students }\end{array}$ & 3.33 & 1.15 & 6 & Medium \\
\hline 18 & I call for human rights respect & 3.36 & 1.13 & 5 & Medium \\
\hline 19 & I support various scientific activities in the local community & 3.45 & 1.03 & 3 & Medium \\
\hline \multirow[t]{2}{*}{20} & $\begin{array}{l}\text { I am convinced that employing information technology and the } \\
\text { Internet in education is one of the most important indicators of } \\
\text { transforming into an information society, which contributes to } \\
\text { increasing the efficiency and effectiveness of education systems. }\end{array}$ & 3.50 & 0.85 & 1 & Medium \\
\hline & The total score of the domain & 3.31 & 0.671 & & Medium \\
\hline
\end{tabular}


last with a mean score of (2.95), and a standard deviation of (1.05) .

This result may be attributed to the fact that the use of technology has opened a new door for students to work, participate and exchange information together outside the confines of the classroom walls that is conducted electronically. The Internet also opens a new door to help students in a classroom engage in various educational activities in the field of research and exchange of information through these activities. Also, technology as a source of communication has opened a wide branch in which the teacher and the student are in constant contact by speaking over the Internet. The greatest potential for new information technology lies in improving the productivity of time spent outside the classroom. Making solutions to problem sets and assigned reading materials available on the Internet provides a lot of convenience. Sending and receiving E-mail immensely simplifies communication between students and teachers and among students who may be engaged in group projects.

- Research domain: The means and standard deviations scores for the responses on the items of research domain were calculated as shown in Table (7):

Table 7 shows that the average means related to the social domain ranged between( 2.27-3.00) from low to medium degrees. The score of the domain as a whole obtained a mean of (2.54) and a standard deviation of (0.857) which indicates a medium degree of teachers' practice of the required roles in light of the digital age demands amidst COVID-19 pandemic.

Item 25 in the Table "I teach my students the scientific way of thinking." ranked first with a mean of (3.00) and a standard deviation of (1.03), whileitem29" I follow e-training for its active role in achieving the goals of professional development for teachers in the digital age" received the lowest score and ranked last with a mean score of (2.27), and a standard deviation of (1.21).

This result may be attributed to the fact that technology helps teachers to develop scientific thinking skills to create environments in which students can learn by doing, receive feedback, and continually refine their understanding and build new knowledge needed in the twenty-first century. Furthermore teacher-student communication can be greatly improved by using classroom technology, it makes teachers' jobs easier to communicate information to their students in a simplified manner and open future horizons for them. Technology can also help teachers know the content that students need in the twenty-first century and create a more personalized learning environment for all types of students to keep them engaged and performing efficiently.

\section{Results of the Second Research Question}

The second research question sought if there are any statistically significant differences $(\alpha=0.05)$ in the degree to which science teachers in the upper basic stage practice the required roles in light of the digital age demands amidst COVID-19from their perspectives due to (gender, years of experience and education sector)variables.

To answer this question, a three-way ANOVA test was performed for the responses on the study instrument. Table (8) shows the means and standard deviations of the degree to which science teachers practice the required roles from their perspectives due to (gender, years of experience and education sector) variables:

Table (8) shows apparent differences in mean scores according to gender, years of experience and education

Table 7: Means and standard deviations scores for the responses on the items of the research domain:

\begin{tabular}{|c|c|c|c|c|c|}
\hline \# & Items & Mean & Standard deviation & Rank & Degree \\
\hline 21 & $\begin{array}{l}\text { I constantly follow scientific developments in my field of } \\
\text { specialization }\end{array}$ & 2.52 & 1.06 & 4 & Medium \\
\hline 22 & $\begin{array}{l}\text { I update my knowledge and skills to be able to absorb modern and } \\
\text { constantly evolving technology }\end{array}$ & 2.63 & 1.04 & 10 & Medium \\
\hline 23 & $\begin{array}{l}\text { I am interested in self-professional development to cope with the } \\
\text { changes of the digital age }\end{array}$ & 2.49 & 1.13 & 9 & Medium \\
\hline 24 & I encourage my students to be innovative and creative & 2.35 & 1.09 & 7 & Medium \\
\hline 25 & I teach my students the scientific way of thinking & 3.00 & 1.03 & 8 & Medium \\
\hline 26 & I rely on experimentation in my fields of work & 2.44 & 0.95 & 2 & Medium \\
\hline 27 & Use more than one source to find information & 2.51 & 0.85 & 6 & Medium \\
\hline 28 & I train my students in scientific research skills & 2.59 & 0.95 & 5 & Medium \\
\hline 29 & $\begin{array}{l}\text { I follow e-training for its active role in achieving the goals of } \\
\text { professional development for teachers in the digital age }\end{array}$ & 2.27 & 1.21 & 3 & Low \\
\hline \multirow[t]{2}{*}{30} & $\begin{array}{l}\text { I help students to transform abstract concepts into concepts related } \\
\text { to reality }\end{array}$ & 2.68 & 1.27 & 1 & Medium \\
\hline & The total score of the domain & 2.54 & 0.857 & & Medium \\
\hline
\end{tabular}


Table 8: The means and standard deviations of the degree to which science teachers in the upper basic stage practice the required roles in light of the digital age demands amidst COVID-19 from their perspectives due to (gender, years of experience and education sector) variables:

\begin{tabular}{|c|c|c|c|c|c|c|c|c|c|c|}
\hline \multirow[b]{3}{*}{ Domain } & \multirow[b]{3}{*}{ Gender } & \multirow[b]{3}{*}{ Education sector } & \multicolumn{8}{|c|}{ Experience } \\
\hline & & & \multicolumn{2}{|c|}{ Less than 5} & \multicolumn{2}{|l|}{$5-10$} & \multicolumn{2}{|c|}{ More than 10} & \multicolumn{2}{|l|}{ Total } \\
\hline & & & Mean & $S D$ & Mean & $S D$ & Mean & $S D$ & Mean & $S D$ \\
\hline \multirow[t]{9}{*}{ Technological } & \multirow[t]{3}{*}{ Male } & Private & 3.22 & 1.220 & 2.17 & 0.530 & 1.69 & 0.540 & 2.65 & 1.1600 \\
\hline & & Public & 3.22 & 0.111 & 2.62 & 0.801 & 2.70 & 0.571 & 2.73 & 0.612 \\
\hline & & Total & 3.22 & 1.100 & 2.42 & 0.691 & 2.43 & 0.710 & 2.69 & 0.921 \\
\hline & \multirow[t]{3}{*}{ Female } & Private & 2.57 & 0.720 & 2.84 & 0.830 & 2.31 & 0.691 & 2.60 & 0.752 \\
\hline & & Public & 2.94 & 0.741 & 2.23 & 0.812 & 2.43 & 0.912 & 2.54 & 0.872 \\
\hline & & Total & 2.72 & 0.751 & 2.50 & 0.8601 & 2.40 & 0.855 & 2.56 & 0.824 \\
\hline & \multirow[t]{3}{*}{ Total } & Private & 2.75 & 0.920 & 2.68 & 0.811 & 2.10 & 0.691 & 2.61 & 0.882 \\
\hline & & Public & 2.97 & 0.710 & 2.32 & 0.812 & 2.51 & 0.826 & 2.58 & 0.821 \\
\hline & & Total & 2.83 & 0.850 & 2.48 & 0.820 & 2.41 & 0.802 & 2.59 & 0.841 \\
\hline \multirow[t]{9}{*}{ Social } & \multirow[t]{3}{*}{ Male } & Private & 3.31 & 1.320 & 2.78 & 1.450 & 3.84 & 0.961 & 3.31 & 1.260 \\
\hline & & Public & 3.37 & 2.310 & 3.29 & 0.461 & 3.31 & 0.542 & 3.31 & 0.733 \\
\hline & & Total & 3.32 & 1.380 & 3.06 & 0.991 & 3.46 & 0.683 & 3.31 & 1.021 \\
\hline & \multirow[t]{3}{*}{ Female } & Private & 3.19 & 0.610 & 3.58 & 0.880 & 3.56 & .7500 & 3.36 & 0.722 \\
\hline & & Public & 3.24 & 0.601 & 3.33 & 0.801 & 3.57 & 0.701 & 3.40 & 0.701 \\
\hline & & Total & 3.21 & 0.600 & 3.44 & 0.830 & 3.57 & 0.702 & 3.38 & 0.712 \\
\hline & \multirow[t]{3}{*}{ Total } & Private & 3.22 & 0.851 & 3.39 & 1.051 & 3.65 & 0.791 & 3.35 & 0.891 \\
\hline & & Public & 3.26 & 0.771 & 3.32 & 0.720 & 3.49 & 0.661 & 3.38 & 0.711 \\
\hline & & Total & 3.23 & 0.811 & 3.35 & 0.872 & 3.53 & 0.690 & 3.36 & 0.792 \\
\hline \multirow[t]{9}{*}{ Research } & \multirow[t]{3}{*}{ Male } & Private & 3.65 & 1.040 & 3.02 & 1.631 & 4.39 & 0.790 & 3.67 & 1.171 \\
\hline & & Public & 4.10 & 0.330 & 3.55 & 0.810 & 4.05 & 0.654 & 3.92 & 0.680 \\
\hline & & Total & 3.72 & 0.971 & 3.32 & 1.180 & 4.14 & 0.683 & 3.80 & 0.954 \\
\hline & \multirow[t]{3}{*}{ Female } & Private & 3.75 & 0.831 & 4.13 & 0.812 & 4.44 & 0.662 & 3.97 & 0.831 \\
\hline & & Public & 3.89 & 0.480 & 4.01 & 1.141 & 4.16 & 0.894 & 4.03 & 0.861 \\
\hline & & Total & 3.81 & 0.701 & 4.06 & 1.000 & 4.23 & 0.841 & 4.01 & 0.841 \\
\hline & \multirow[t]{3}{*}{ Total } & Private & 3.72 & 0.880 & 3.87 & 1.110 & 4.43 & 0.671 & 3.89 & 0.942 \\
\hline & & Public & 3.91 & 0.470 & 3.90 & 1.081 & 4.13 & 0.811 & 4.01 & 0.820 \\
\hline & & Total & 3.79 & 0.750 & 3.89 & .0811 & 4.20 & 0.780 & 3.95 & 0.871 \\
\hline
\end{tabular}

sector variables, and to determine their effect, the three-way MANOVA test was performed, as shown in Table 9:

Table 9 indicates that there are no statistically significant differences $(\alpha=0.05)$ in science teachers' practice attributed to gender, years of experience or education sector which means that teachers' practice did not differ from their perspectives due to the variables of gender, years of experience or education sector they work in.
The teachers' consensus on the degree to which they practice the required roles amidst COVID-19 may be attributed to the fact that both male and female teachers (regardless of their experience and the education sector) have extensive knowledge and practice of these roles, and therefore their views are the same. Furthermore, the Corona pandemic has hit the education system hard without exception, and therefore the ministry of education has taken the same measures for male and female teachers, 
Table 9: Results of the three-way MANOVA test for the effect of gender, years of experience and education sector on the domains of science teachers practice for the required roles in light of the digital age demands amidst COVID-19

\begin{tabular}{|c|c|c|c|c|c|c|c|}
\hline Source & \# & Dependent variables & $\begin{array}{l}\text { Type sum of } \\
\text { squares }\end{array}$ & $d f$ & Mean square & $F$ & $\operatorname{Siq}(P)$ \\
\hline \multirow[t]{3}{*}{ Gender } & 1 & Technological & 0.830 & 1 & 0.8300 & 1.217 & 0.27 \\
\hline & 2 & Social & 0.318 & 1 & 00.318 & .5040 & 0.48 \\
\hline & 3 & Research & 1.801 & 1 & 1.801 & 2.432 & 0.12 \\
\hline \multirow{3}{*}{$\begin{array}{l}\text { Years of } \\
\text { experience }\end{array}$} & 1 & Technological & 4.280 & 2 & 2.099 & 2.039 & 0.15 \\
\hline & 2 & Social & 2.530 & 2 & 1.265 & 2.006 & 0.14 \\
\hline & 3 & Research & 4.566 & 2 & 2.333 & 1.957 & 0.17 \\
\hline \multirow{3}{*}{$\begin{array}{l}\text { Education } \\
\text { sector }\end{array}$} & 1 & Technological & .3990 & 1 & .3990 & .5850 & 0.45 \\
\hline & 2 & Social & .1150 & 1 & .1150 & .1830 & 0.67 \\
\hline & 3 & Research & 0.010 & 1 & 0.010 & 0.014 & 0.91 \\
\hline \multirow[t]{3}{*}{ Error } & 1 & Technological & 94.085 & 138 & .6820 & & \\
\hline & 2 & Social & 87.042 & 138 & .6310 & & \\
\hline & 3 & Research & 102.179 & 138 & 0.740 & & \\
\hline \multirow[t]{3}{*}{ Total } & 1 & Technological & 100.513 & 142 & & & \\
\hline & 2 & Social & 89.744 & 142 & & & \\
\hline & 3 & Research & 108.555 & 142 & & & \\
\hline
\end{tabular}

Statistically significant at $(\alpha=0.05)$

in private and government schools, for all age groups and experiences which led to the absence of statistically significant differences.

\section{Conclusion}

The study concluded that the degree to which science teachers in the upper basic stage practice the required roles in light of the digital age demands during (COVID-19) pandemic was moderate, the results also indicated that there were no statistically significant differences in the degree of science teachers practice attributed to gender, years of experience and education sector variables.

\section{Recommendations}

Based on the results of the current study, the researchers recommend the following:

- Educating science teachers about the importance of practicing the required roles in light of the digital age demands during (COVID-19) pandemic.

- Developing science school teachers across different types of programs, courses and workshops in which the required roles of the digital age are activated.

- Suggesting that the teacher's guide include strategies and teaching methods that support teachers' role.
- Activating the role of supervisors in following up science teachers and increasing their practice of the required roles in light of the digital age demands.

\section{References}

Al Yami, H. (2020). A proposed training program to develop digital teaching skills for female teachers in the Kingdom of Saudi Arabia.College of Education Journal, Al-Azhar University, 85, (2), 11-61.

Albalawi, A. (2019). Perception of a proposal training program for the development of the twenty-first century skills in mathematics parameters in Tabuk City. Arab studies magazine in Education and Psychology, Arab Educational Association,107, 387-433.

Al-Ghamdi, S. \&Ruwaili, S. (2020). The digital learning experience in teaching science and mathematics from the teachers' perspectives.Journal of Humanities and Social Sciences Studies, Center for Research and Development of Human Resources (Ramah), 3(4), 14-39.

Al-Olaymat, A. (2020). The degree to which science teachers' in the upper basic stage practice the competencies of education Technology. Journal of the Islamic University of Educational and Psychological Studies, 28 (6), 224-238.

Alrasa'i, M. (2017).Building a list of science teachers competencies in ICT and measuring their availability before service. Journal of the University of Hussein bin Talal Research, V 2. 
Anil, A. (2019). Education in the 21 st Century: The Dynamics of Change. Research, journal of social sciences, 10(3). 128-133.

Atteberry, A, \& Andrew McEachin, A. (2020). School's Out: The Role of Summers in Understanding Achievement Disparities. American Educational Research.

Hayaki, M. (2017).The level of digital empowerment in education among the teachers of the middlestage in the Kingdom of Bahrain.Journal of Yarmouk University, 44 (2), 1-65.

Stols G., Ferreira, R., Palser, A., Olivier, W., Venter, S., \&Vandermerwa, A. (2015). Perceptions and needs of South African Mathematic teachers concerning their use of technology for instruction South African Journal of Education, 35)4),1-13.
Yıldırım, F.S. \& Mirici, S. (2016). Improving the student's opinion about the nature of science with the processbased activities by the teachers who get distance education about the nature of science. International Online Journal of Education and Teaching (IOJET), 3(4). 262-283. http://iojet.org/index.php/IOJET/article/ view/151/141

Yue, X. (2019).Exploring Effective Methods of Teacher Professional Development in University for 21st Century Education. International Journal of Innovation, Education and Research, 7(5), 248-257.

Zaragoza, M. C., Díaz-Gibson, J., Caparrós, A. F., \&Solé, S. L. (2019). The teacher of the 21st century: professional competencies in Catalonia today. Educational Studies, 1-21. 